\title{
ЭСТЕТИКА
}

\author{
В.Н. Сибиряков
}

\section{КОНЦЕПЦИИ И ПОДХОДЫ К ЭСТЕТИЧЕСКОЙ ИНТЕРПРЕТАЦИИ ЗВУКОЗАПИСИ}

Аннотация. Расширяя традиционное понятие музыкальной звукозаписи, автор вводит его в контексте современной эстетики. В статье рассматриваются наиболее репрезентабельные научные концепции изучения звукозаписи, где предметом исследования выступает генезис её эстетических и художественных характеристик. С установкой на эстетическую интерпретацию приводятся такие концепции, как "аура», "абсолютная музыка», "диалектика общих и отдельных онтологических закономерностей звучащей материи», "креативная симуляция» и др., а также предлагаются различные методологические подходы к изучению искусства звукозаписи. Анализируются и соотносятся отечественные и зарубежные исследования, соприкасающиеся с темой звукозаписи, с целью выявить наиболее существенные закономерности данного процесса. В музыкальном искусстве в эпоху её технической воспроизводимости наблюдается возобновление ауры в её качественно новой форме. Современный этап также характеризуется альтернативным восприятием музыки вопреки традиционному опыту слушания. Новизна представленного анализа - интерпретация художественно феномена звукозаписи в системе философской и эстетической рефрлексии, что даёт ключ к пониманию многих явлений в музыкальной науке, и представляет значительный интерес для теории искусства XX и XXI в8.

Ключевые слова: звукозапись, эстетика, техническая воспроизводимость, абсолютная музыка, концепция ауры, эмбиент, философия звука, эстетическая интерпретация, слуховой опыт, звукорежиссура.

Abstract. Expanding the traditional concept of musical sound recordings, the author introduces it in the context of contemporary aesthetics. The article considers the most significant scientific concept of sound recording's study, where the subject of research is the genesis of its aesthetic and artistic characteristics. With the installation of the aesthetic interpretation author explores concepts of "aura", "absolute music", "the dialectic of the general and specific ontological regularities of sounding matter", "creative simulation" et al., and also offers a variety of methodological approaches to the study of the sound recording art. Analyzes and correlates local and foreign research, which related to the topic of sound recording, in order to identify the most significant patterns in this process. In the art of music in the Age of Technical Reproduction there is resumption of in its aura of a qualitatively new form. The modern stage is also characterized by an alternative perception contrary to the traditional music listening experience. The novelty of the presented analysis consists in the interpretation of the artistic phenomenon in the sound recording system of philosophical and aesthetic reflection that provides the key to understanding of many things in musical science and offers substantial interest in the theory of art of the XX and XXI centuries.

Key words: aural experience, sound recording, aesthetic, technical reproducibility, absolute music, concept of aura, ambient, philosophy of sound, aesthetic interpretation, sound engineering.

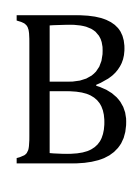

опрос о философско-эстетическом осмыслении звукозаписи имеет сравнительно недавнюю историю. Поскольку становление звукозаписи шло параллельно с развитием радио, фотографии и кинематографа, взаимно влиявших друг на друга, то вопрос о художественноэстетическом статусе звукозаписи, так или иначе, обсуждался в профессиональных кругах. Однако если к настоящему моменту проблеме кинематографа и фотографии было посвящено достаточно много теоретических, искусствоведческих и философских исследований, то такой научной литературы в области звукозаписи явно недостаточно.
Такое положение связанно со многими сложностями изучения аудиального канала восприятия, его эстетического осмысления, а так же отчасти с доминированием визуальной культуры в современном мире.

Несмотря на это среди англоязычной литературы по данной теме можно встретить труды таких исследователей, как А. Хамильтон (A. Hamilton), Д. Суисмэн (D. Suisman), М. Катц (M. Katz), Г. Милнэр (G. Milner), В. Ирлмэн (V. Erlmann), Д. Туп (D. Toоp), в которых звукозапись рассматривается скорее как историко-культурологический феномен в рамках социальных или социально-эконо- 
мических отношений. Интересные исследования в рамках социологии музыки Т. Адорно, К. Блаукопфа. В узкоспециализированной литературе, описывающей практический опыт звукорежиссуры, частично раскрыты эстетические характеристики звукозаписи такими авторами, как Б. Овсински (B. Owsinski), Д. Гибсон (D. Gibson), Д. Соненшайн (D. Sonnenschein), Р. Изаки (R. Izhaki) и др.

Среди отечественных исследователей историческим становлением звукозаписи и её отдельными вопросами занимались А.М. Лихницкий, А.А. Шерель, Е.В. Дуков, А.В. Тихонов, В.Г. Динов, А. Вейценфельд, П.К. Кондрашин и др. И.А. Алдошина и ряд других специалистов рассматривали данный вопрос с позиции психоакустики. Так же интересными для настоящего исследования представляются общефилософские, музыковедческие и искусствоведческие работы Е.В. Назайкинского, Т.В. Чередниченко, Г. Орлова, В.И. Мартынова, Ю.В. Стракович и др.

Изучение влияния музыкальной звукозаписи на социокультурную среду представляет значительный интерес для теории искусства XX в. Осознание и интерпретация этого художественноэстетического феномена в системе философской и эстетической рефлексии, а также её исторические предпосылки дают ключ к пониманию многих явлений в музыкальной науке и культурной реальности в целом. Тем не менее, несмотря на значительный вклад отечественных и зарубежных авторов в исследование звукозаписи, вопрос о её месте в контексте современных философских исследований и эстетических теорий остаётся всё ещё открытым.

Под процессом записи звуковой информации подразумевается творческая звукозапись, в которой фиксация художественно-опосредованного звукового объекта является основной задачей, что и представляет научный интерес настоящей работы. В последнее время звукозапись, будучи результатом творческой деятельности звукорежиссёра, стала пониматься в целом как самобытное художественное явление, как самостоятельное технически воспроизводимое искусство. Но в качестве рабочей установки наиболее важным для эстетического анализа будет дискурс о выразительно-интерпретативных функциях звукозаписи, выражающий определённое отношение к записываемому материалу и исключающий предмет искусства в привычном нашем понимании из сферы эстетической рефлексии.

Вырабатывая определённые подходы к изучению феномена звукозаписи, на наш взгляд, следует выделить основные составляющие предмета изучения: звук как физическое явление и его куль- турная селекция в сфере творчества и запись как техническое средство регистрации или фиксации явлений и фактов, обладающая коммуникативным актом. Исходя из этого, можно выделить две линии эстетико-философского анализа рассматриваемого предмета: первая рассматривается в культурологическом аспекте и занимает значительное место в музыкальной эстетике, вторая рассматривается в контексте философии техники, развивающаяся в экзистенциальном и антропологическом направлениях. В силу широкого круга междисциплинарных связей каждой из такой линии, мы рассмотрим наиболее репрезентабельные концепции.

Итак, звукозапись или «фонография» с каждым годом после своего открытия технически совершенствовалась и полностью себя реализовала, в первую очередь, в области музыкального искусства, но с какими проблемами эстетики она столкнулась, какое отношение она сформировала к музыке и к акустическому явлению в целом? Эти и многие другие вопросы можно свести к одному: как бытийствует в качестве эстетического средства то, что мы называем звукозаписью?

История звукозаписи берет начало в середине XIX в. на фоне переосмысления многих сфер человеческой жизнедеятельности, начиная от научных открытий, подготавливающих почву для технической революции и кончая радикальными изменениям в художественном опыте, предвосхитившим переход от элитарного искусства к массовому в $\mathrm{XX}$ в. В этот переходной период, «когда элита перестаёт быть ведущей силой культуры, а масса, оказавшись предоставленной себе, начинает требовать от искусства гипертрофии гедонистической функции, понимая её по-своему» [1, с. 23], эстетические представления, созданные элитой эпохи Просвещения, начали основательно подвергаться критике. Наряду с такими изменениями стали появляться новые тенденции в музыкальной эстетике, которые снова поднимали вопросы о сущности музыки, о её языке и функционировании.

Автор одной из известных работ по теории медиа середины прошлого столетия - В. Беньямин в своём труде «Произведение искусства в эпоху его технической воспроизводимости», задаваясь вопросом о статусе кино и фотографии, с появлением которых обесценивается уникальное бытие «здесь и сейчас» в искусстве, конечно, нашёл бы над чем задуматься также и в области механической репродукции музыки. Многие рассуждения, связанные с подобной темой, часто апеллируют именно к этой работе, в которой сформулированы основные тезисы о трансформации восприятия реципиента и художественного отражения действи- 
тельности, рождая новые эстетические формы под воздействием аппаратуры на примере кино и фото. Замена уникального проявления массовым, ликвидация традиционных ценностей, потеря «ауры» произведения, «приватизация» предметов искусства, формирование рассеянного внимания и т.д. - эти все выводы Беньямина применимы и в отношении звукозаписи, которые стоит рассмотреть в ходе нашего анализа более детально.

На современном этапе главные атрибутивные свойства технически опосредованного художественного произведения всё чаще стали проявлять себя не в традиционных эстетических категориях «прекрасного», «изящного» и др., а в таких понятиях как «художественная энергетика», «атмосфера», «драйв», которые могут быть синонимами понятия «ауры». В век репродукций и тиражирования это понятие стало основой для осознания демаркационной черты между уникальным и банальным в искусстве. В нынешней музыкальной культуре, в частности в звукозаписи «ауратическая» концепция, несомненно, присутствует, хотя и понимается неоднозначно в зависимости от тех или иных установок восприятия, которые можно рассмотреть в двух подходах - в категориях совершенства и несовершенства, оперирующих методами минимального вмешательства в музыку или её полной творческой модификации. В рамках второй установки, на вопрос могут ли представить электронные технологии музыку столь жизнеспособной как в концертных практиках, «ауратическая» концепция даёт положительный ответ. Это объясняется ещё и тем, что физический носитель музыкального объекта, стал предметом эстетического опыта - реально осязаемым и ценностно-окрашенным, и внёс существенные изменения в слуховой опыт. В таком случае мы имеем дело с появлением нового измерения в практике слушания, что «ведёт вовсе не к «освобождению предмета от культовой оболочки» и укоренению в политической практике, а к формированию новой «ауры»» [2].

Формирование нового мировоззренческого отношения к звуку, к акустическому явлению как таковому, его структуре, а также социальному функционированию, происходившее не без участия звукозаписи, позволило понять, что музыка является конкретным и локальным культурным феноменом, зависящим от установок определённой эпохи и традиции. Наиболее подробно это описано в работе А. Богомолова «Метафизика звука в западноевропейской культуре», где автор, пытаясь ответить на вопрос «что такое музыка» в поисках её оснований и глубинных связей с культурой, развивает ряд идей интересных и для нашего исследования.
Формулируя основной тезис, что «музыка появляется в точке соприкосновения звука и культуры» [3, с. 23] (изначально в истории это проявлялось в качестве фольклора), вслед за Лосевым автор вводит атрибуцию оппозиции музыкального «становления - ставшего». Под последним понимается письменно зафиксированная сложившаяся музыкально-теоретическая система, которая став частью традиции, фиксирует свои нормативные границы, устанавливающие «музыкальное» из всех звуковых событий и формирует у человека, вовлечённого в такую традицию свой «горизонт ожидания», от которого и зависит понимание музыки. Вне этих границ, за «горизонтом ожиданий» как некой парадигмы музыкальный образ теряет свою эстетическую ценность, что и стало реализовываться с начала XX в. на фоне смены парадигм.

Написанная музыка, musica inscripta - это музыкальное ставшее, которое превращает живую музыкальную практику в застывший отпечаток текст. Становление же, в противоположность ставшему, выражает «...процессуальность феномена музыкального в чистом виде, ...оно существует до любой формализованной культурной интерпретации и ...онтологически первично к любому описанию» [3, с. 43-45]. Автор обращается именно к этой форме, которая не сводится только к физическим или психическим характеристикам и далее расширяет понятие «музыки как становление», включая его в пространство чистого слушания, в «метафизику звука», где потенциально содержатся все «музыки» различных эпох.

Однако если автор, пользуясь методом редукции, отчищает музыку от эстетического восприятия и всех её акцидентальных свойств, то в нашем случае нужен обратный процесс - исходя из внутренних слоёв звучащих структур или «метафизики звука», попытаться осмыслить в общих чертах эстетическое многообразие записанной музыки современной мультипарадигмальной эпохи.

Исходя из таких положений, что же можно сказать о звукозаписи? Если нотная запись ограниченная и строго зафиксированная в традиции, в случае живого исполнения передаёт неполную, условную и весьма схематичную музыкальную информацию, то звукозапись воспроизводит записанное буквально.

Будучи зафиксированным на материальном носителе, музыкальный объект становится таким же процессуальным, как и музыкальное становящееся. Нарушая внешние пространственные измерения в музыке - от нотной записи к фонографии, как от наглядного способа фиксации к буквально- 
му, звукозапись вытесняет собой музыку как таковую в привычном нашем понимании. Другими словами, включая звукозапись в диалектику общих и отдельных онтологических закономерностей музыкального искусства можно сказать, что звукозапись, становясь «застывшей» деятельностью превращает музыкальное произведение уже в «сырой материал». Так с древнейших времён звук, будучи материалом природы, преобразуется через опредмечивание творческих сил человека в «sonus cultus», в основанное на пифагорейском учении ладообразование, где последнее, в свою очередь, выступает как квазиприродные законы музыки, которые надстраиваются «...над ладовыми системами как новая “человеческая форма”, а по отношению к позднее возникающей в европейской культуре индивидуализированной авторской композиции снова выступают как “квазиприрода” музыки» [4]. Нормативно-жанровая предметность XII-XVII вв., став «сырым материалом», переходит в индивидуальное произведение XIX-XX вв., а далее в такую диалектическую модель включается и звукозапись. Так, например, обстоит дело с «диджеингом» или «семплированием», которые представляют собой радикальное изменение традиционных музыкально-эстетических ценностей.

Подобные рассуждения мы можем встретить у создателя музыки «эмбиент» Брайана Ино, который говорил, что к началу XIX в. формируется полный состав оркестра, открывая тем самым новую музыкальную эпоху. Век спустя последовало изобретение звукозаписи, появление которой по значимости в музыкальном мире стало равноценно с введением в обиход оркестрового исполнительства. Записанная музыка обретает новую жизнь, а технология её создания позволяет художникам теперь проводить над ней самые изощрённые эксперименты. «B XX веке музыка будет каждый раз создаваться заново - посредством взаимодействия компьютера и человека» [5].

C XIX столетия музыка стала активно развиваться в своей новой форме - в рамках открытого академического концерта, в котором устраняется всякий внехудожественный контекст восприятия (как это было в ритуально-церемониальном и обрядовом пространстве) и активизируется автономный статус музыкального искусства. Формат концерта постепенно изменяет опыт и восприятие слушателя, делает акцент на резком функциональном разделении на исполнителей и слушателей, а «...то, что раньше могло казаться в музыке ясным, очевидным, само собой разумеющимся, нуждалось теперь в ином осмыслении, внимательном вслушивании, конкретном разумении» [6, с. 13].
C появлением фонографа такое эстетическое восприятие по идее должно было усиливаться. Поскольку в концерте всё ещё остаётся визуальная составляющая в виде жестов, света, движения различных частей тела, передающих эмоции, то музыкальное выражение продолжает оставаться программным и комплексным, тогда как фонограф полностью лишает музыку наглядности. Отсутствие визуального в звукозаписи, с одной стороны, может быть созвучно с понятием «абсолютной музыки», с идеальным восприятием искусства звуков. Утверждая, что оперу - как самый визуальный из музыкальных жанров - на самом деле лучше услышать на записях, т.е., не видя костюмы и декорации, отвлекающих внимание слушателя, Адорно в своей статье поясняет: «лишённая фальшивой шумихи, долгоиграющая пластинка одновременно освобождает себя от капризности поддельных оперных фестивалей. Это позволяет музыке достичь оптимальной презентации, предоставляя ей возможность возвратить часть силы и интенсивности, которая была изношена в оперных театрах» [7, с. 284].

С другой стороны, термин «абсолютная музыка» из музыкальной эстетики XIX в., введённый Р. Вагнером в 1846 г. и означающий высшие выразительные возможности самостоятельного искусства звуков, противоречил идеи синтеза искусств - важнейшему элементу в музыке романтизма. Сам Вагнер уже через несколько лет меняет это первоначальное значение на так называемое «..."частичное искусство”, отделившееся от своих корней (слова и танца в древнегреческой трагедии) и потому опустившееся до уровня “пустой абстракции”» [8, c. 318]. Тем не менее, представляется, что именно первое значение данного термина хорошо согласуется с эстетикой звукозаписи второй половины $\mathrm{XX}$ в., которая сформировалась в качестве одного из направлений драматургической звукорежиссуры - записи предельно рафинированного музыкального произведения. Такие установки были характерны для звуковоспроизводящих систем названных маркетинговым термином «hi-fi».

Казалось бы, цель достигнута - теоретически можно было в домашних условиях, закрыв глаза, почувствовать себя на концерте Венского филармонического оркестра в Золотом зале Музикферайна и погрузиться в глубину звуковой ткани, в идеальное звучание «абсолютной музыки». Вдобавок ко всему, будучи связанным с материальностью записанной музыки, эстетический опыт усиливался, а сами физические артефакты или носители информации (грампластинки) при этом были уже нечто большим, чем просто звуки музыки. Однако это было уделом немногих ценителей и коллекционеров и 
продлилось всего несколько десятилетий, упразднившись в цифровой эпохе, что было связано с формированием нового культурного кода, новым отношением к музыке и её прослушиванию.

Такое положение восходит к всё той же концертной практике с её поздним стереотипом «исполнитель - слушатель», о чём убедительно рассказывает В. Мартынов. По его словам, восприятие музыки в такой парадигме утрачивает способность пребывать внутри звука. В работе «Зона opus posth, или Рождение новой реальности» автор прослеживает эволюцию григорианского пения к композиторской opus-практике как вытеснение из сакрального и выделение исключительно эстетического качества, от нотной записи к фонографии с обесцениванием первой. Исследователь, связав идеи Р. Барта и М. Фуко о «смерти автора», говорит также и о завершении эпохи композиторов, которая в свою очередь должна по идее привести к «новому сакральному пространству». Здесь он обращается к традиции богослужебного пения и связывает свои предположения с концепцией «глобальной деревни» М. Маклюэна. Однако, говоря о нынешнем состоянии Мартынов замечает, что музыка перестала быть событием (будь то церемониал или концерт или даже прослушивание пластинки), она теперь не функциональна как, например, часть богослужения и не автономна как классическая музыка, музыка потеряла смысл и самое главное - идеологию.

Действительно, с одной стороны, включившись в процесс коммодификации, из музыкального произведения и его репродукции постепенно выхолащивались традиционные эстетические и духовные ценности, в результате чего сформировалось рассеянное внимание к прослушиванию, а сама музыка потеряла своё изначальное качество, вызывающее благоговение. Отделившись от своих корней, именно «частичная музыка» в поправленном вагнеровском значении стала распространённым феноменом в виде звукозаписи и служит теперь в качестве «обоев» социокультурного цифрового пространства, не требующих к себе внимания и высокой точности «имитативно-репрезентативного» звуковоспроизведения, как того добивались, например, в системе «hi-fi».

С другой стороны, в современную эстетику в качестве рабочей категории приходит понятие «атмосфера», именно поэтому в 1990-е гг. популярность «эмбиент» как музыкального направления, в основном существующего как звукозапись, становится оправданной и отвечает эстетическим запросам XXI в. Предтечей такой эстетической интерпретации музыки был Эрик Сати, ещё в начале прошлого столетия предложивший свою кон- цепцию «меблировочной музыки». Об этой новой практике слушания Брайан Ино пишет: «Эмбиент должен предусматривать несколько уровней погружения слушателя, не выделяя ни один из них: он должен быть столь же незаметен, насколько интересен» $[9$, с. 21].

Креативно-симуляционный $[10$, с. 20] процесс репрезентации музыкального произведения, который стал преобладающим в звукорежиссуре, создание нового виртуального акустического пространства, тембральных и звуковысотных соотношений путём применения различных эффектов и специального звукового оборудования, саунд-дизайна и технологии пост-продакшн - всё это расширяет эстетический опыт и становится полноправным участником творческого процесса наравне с композиторством и исполнительством. Несмотря на то, что музыка к настоящему моменту практически полностью интегрирована в интернет-пространство и является дополнительным медиаконтентом IT-технологий, она продолжает выполнять свою эстетическую функцию.

Таким образом, исходя из проделанного анализа можно сделать некоторые выводы: музыкальное искусство в эпоху технической воспроизводимости если и теряет свою прежнюю ауру (в её беньяминовском понимании), то со временем, несомненно, приобретает другую качественно новую форму; применение метода феноменологической редукции в изучении звукозаписи, отсылающего к «метафизике звука» даёт возможность найти определённые закономерности построения звучащей материи в «sonus cultus»; потенциально существующую в звукозаписи возможность традиционного восприятия музыки можно выразить в концепте «абсолютной музыки», её достижения через очищенное от других модусов акустическое восприятие, однако на современном этапе доминирующую позицию занимает инверсия такого концепта.

Существует ещё много отличительных качеств, выраженных в новых эстетических формах и опыте, не укладывающихся в рамки данной работы и требующих дальнейшего рассмотрения. Например, современный исследователь музыкальных технологий М. Катц перечисляет семь таких отличительных качеств звукозаписи, которые делают фонографический опыт уникальным: «осязаемость», «портативность», «(не)видимость», «повторяемость», «темпоральность», «рецептивность» и «манипулятивность». Таким образом, приведённый в данном исследовании анализ проблем, связанных с осмыслением звукозаписи в философии музыки и музыкальной эстетике раскрывает лишь малую часть всех заявленных концепций. 


\section{Список литературы:}

1. Очерки эстетики и теории искусств XX века / Отв. ред. Н.А. Хренов, А.С. Мигунов. М., 2013. С. 23.

2. Агамбен Дж. Станцы. Слово и фантазм в культуре Запада / Пер. с ит. Б. Дубина. URL http://kinoart.ru/archive/1998/11/ n11-article21.

3. Богомолов А.Г. Метафизика звука в западноевропейской культуре. М., 2012. С. 23.

4. Эстетика музыкальная // Музыкальная энциклопедия / Под ред. Ю.В. Келдыша. М.: Советская энциклопедия, Советский композитор, 1973-1982.

5. Брайан Ино: о твиттере, пластилине и коллективном разуме. URL: http://www.lookatme.ru/flow/posts/artradar/111399-brayan-ino-o-tvittere-plastiline-i-kollektivnom-razume\#comments.

6. Михайлов А.В. Музыкальная эстетика Германии XIX в. М., 1981. Т. 1. С. 13.

7. Adorno Theodor. Opera and the Long-Playing Record / trans. Thomas Y. Levin, in Essays on Music, ed. Richard Leppert. Berkeley and Los Angeles: University of California Press, 2002. P. 284.

8. Лексикон нонклассики. Художественно-эстетическая культура ХХ века. / Под ред. В.В. Бычкова. М., 2003. С. 318.

9. Туп Д. Океан звука. М.: АСТ; Адаптек, 2007. С. 21.

10. Кущ Е.В. Фонокультура как новая парадигма акустического пространства // Культурная жизнь Юга России. № 1(48). Краснодар, 2013. С. 20.

11. Никитина И.П. Эстетика и художественная критика // Философия и культура. 2010. № 7. С. 67-75.

12. Синеокий О.В. Восточный рок: звукозапись из социалистической Азии // Человек и культура. 2013 . № 6. С. 1-22. DOI: 10.7256/2409-8744.2013.6.7072. URL: http://www.e-notabene.ru/ca/article_7072.html.

13. Петрусева Н.A. О двух тенденциях Новой музыки // NB: Филологические исследования. 2013. № 3. С. 177-233. DOI: 10.7256/2306-1596.2013.3.10184. URL: http://e-notabene.ru/fil/article_10184.html.

14. Шапинская Е.Н., Киященко Н.И. Диалог об эстетическом воспитании: кризис ценностей и пути его преодоления // Культура и искусство. 2014. № 4. C. 417-427. DOI: 10.7256/2222-1956.2014.4.12885.

15. Буева Л.П. Воображение как стимулятор искусства // Психология и психотехника. 2014. № 8. С. $863-879$. DOI: $10.7256 / 2070-8955.2014 .8 .12561$.

16. Евстигнеева Е.В. Психология восприятия музыки в трактовке А. Шопенгауэра // Психология и психотехника. 2010. № 7. С. 54-60.

17. Розин B.M. Сущность и тайна музыки // PHILHARMONICA. International Music Journal. 2014. № 2. C. $194-218$. DOI: $10.7256 / 1339-4002.2014 .2 .13588$.

18. Холопова В.Н. Специальное и неспециальное музыкальное содержание // PHILHARMONICA. International Music Journal. 2014. № 1. C. 14-25. DOI: 10.7256/.2014.1.1240.

\section{References (transliterated):}

1. Ocherki estetiki i teorii iskusstv XX veka / Otv. red. N.A. Khrenov, A.S. Migunov. M., 2013. S. 23.

2. Agamben Dzh. Stantsy. Slovo i fantazm v kul'ture Zapada / Per. s it. B. Dubina. URL http://kinoart.ru/archive/1998/11/n11article21.

3. Bogomolov A.G. Metafizika zvuka v zapadnoevropeiskoi kul'ture. M., 2012. S. 23.

4. Estetika muzykal'naya // Muzykal'naya entsiklopediya / Pod red. Yu.V. Keldysha. M.: Sovetskaya entsiklopediya, Sovetskii kompozitor, 1973-1982.

5. Braian Ino: o tvittere, plastiline i kollektivnom razume. URL: http://www.lookatme.ru/flow/posts/art-radar/111399brayan-ino-o-tvittere-plastiline-i-kollektivnom-razume\#comments.

6. Mikhailov A.V. Muzykal'naya estetika Germanii XIX v. M., 1981. T. 1. S. 13.

7. Adorno Theodor. Opera and the Long-Playing Record / trans. Thomas Y. Levin, in Essays on Music, ed. Richard Leppert. Berkeley and Los Angeles: University of California Press, 2002. P. 284.

8. Leksikon nonklassiki. Khudozhestvenno-esteticheskaya kul'tura XX veka / Pod red. V.V. Bychkova. M., 2003. S. 318.

9. Tup D. Okean zvuka. M.: AST; Adaptek, 2007. S. 21.

10. Kushch E.V. Fonokul'tura kak novaya paradigma akusticheskogo prostranstva // Kul'turnaya zhizn' Yuga Rossii. № 1(48). Krasnodar, 2013. S. 20.

11. Nikitina I.P. Estetika i khudozhestvennaya kritika // Filosofiya i kul'tura. 2010. № 7. S. 67-75.

12. Sineokii O.V. Vostochnyi rok: zvukozapis' iz sotsialisticheskoi Azii // Chelovek i kul'tura. 2013. № 6. S. 1-22. DOI: 10.7256/2409-8744.2013.6.7072. URL: http://www.e-notabene.ru/ca/article_7072.html.

13. Petruseva N.A. O dvukh tendentsiyakh Novoi muzyki // NB: Filologicheskie issledovaniya. 2013. № 3. S. 177-233. DOI: 10.7256/2306-1596.2013.3.10184. URL: http://e-notabene.ru/fil/article_10184.html.

14. Shapinskaya E.N., Kiyashchenko N.I. Dialog ob esteticheskom vospitanii: krizis tsennostei i puti ego preodoleniya // Kul'tura i iskusstvo. 2014. № 4. S. 417-427. DOI: 10.7256/2222-1956.2014.4.12885.

15. Bueva L.P. Voobrazhenie kak stimulyator iskusstva // Psikhologiya i psikhotekhnika. 2014. № 8. S. 863-879. DOI: 10.7256/2070-8955.2014.8.12561.

16. Evstigneeva E.V. Psikhologiya vospriyatiya muzyki v traktovke A. Shopengauera // Psikhologiya i psikhotekhnika. 2010. № 7. S. 54-60.

17. Rozin V.M. Sushchnost' i taina muzyki // PHILHARMONICA. International Music Journal. 2014. № 2. S. 194-218. DOI: $10.7256 / 1339-4002.2014 .2 .13588$.

18. Kholopova V.N. Spetsial'noe i nespetsial'noe muzykal'noe soderzhanie // PHILHARMONICA. International Music Journal. 2014. № 1. S. 14-25. DOI: 10.7256/.2014.1.1240. 